ARTICLE

DOI: $10.1057 / s 41599-018-0090-z$

\title{
Social media choices and uses: comparing Turkish and American young-adults' social media activism
}

Barbara Ruth Burke ${ }^{1} \&$ Ayșe Fulya Șen ${ }^{2}$

\begin{abstract}
Advocates of new media-especially social networks, blogs, and photo/content sharing sites-argue that these tools create transformative impacts on society. Recently, around the world younger activists in popular democracy movements, uprisings, and protests, feeling disengaged by traditional forms of political discourse, have debated their positions on new media, and have used digital media to communicate, organize, and coordinate protest activities. While some media scholars suggest this is an indication that young people are active in creating a public sphere constructed by social media, there is still little real-world evidence that the technological potentials are widely realized. To address this gap, this comparative case study aims to reveal how some "ordinary" young people are using social media in response to political issues, investigating: if social media create a new kind of dynamic arena for their public activism; which factors may stimulate the young to activism; and whether their motivation is powerful enough to resist the status quo. Describing and analyzing qualitative interview data from a study of Turkish students and a parallel collection of data from US students, we construct an explanation of their communicated understandings of their differences and similarities in opportunities for political actions. Our findings indicate: there are many similar technical capacities; some similar topics are seen as political; and there are different understandings of what is and is not for public discussion among their personal collections of contacts and friends, with varying levels of real-world connections. This analysis is important in terms of understanding the ways uses of media technologies may be affected by different cultures, political and social conceptualizations and online communication patterns.
\end{abstract}

\footnotetext{
${ }^{1}$ University of Minnesota, Morris, Minnesota, USA. ${ }^{2}$ Firat University, Elazig, Turkey. Correspondence and requests for materials should be addressed to B.R.B. (email: burkebr@morris.umn.edu)
} 


\section{Introduction}

ew media is characterized by digitization, convergence, interactivity and the rise of networks. While social networking sites connect people with each other, they also produce additional outcomes. New media, through their interactive capacities, have the potential to undermine established practice and open up the possibility for a more pluralistic public sphere. Furthermore, the development of new media extends individual activity into the collective realm, negotiating interactive communication, user-generated content and variety of alternative sociopolitical and cultural practices (Wessels, 2014).

Technological optimism, which aims at democratic renewal, is based upon acknowledging the open and collaborative networking characteristics of social media (Loader and Mercea, 2011). Internet-created, networked communication channels, available in new media platforms, also offer a diversity of communicators a dynamic and wide range of possibilities, and may create several forums for participation in social and political issues. No longer are large institutions, organizations, governments and political parties the sole sources of mediated political messages. Instead, alternative and critical channels created by new mobile and inexpensive technologies may create discourse arenas/public spheres for debating individuals and groups. Bennett (2003) explains, activist networks use new digital media to coordinate activities, plan protests, and publicize high-quality information about their causes. Norris (2007) emphasizes that in today's world, (with) alternative channels of political engagement, mobilization and expression rapidly emerge in modern societies, including the general rise of demonstrations and protest politics.

New communication technologies enable a "networked young citizen," with political attitudes and identities increasingly shaped less by ties to family, neighborhood, school or work, than by the manner in which they participate and interact through social networks, which they have had a significant part in constructing (Loader et al., 2014, p 143). Social media thus can become viable alternative spaces, where collective activism is constituted and negotiated; and media are used to influence participation in collective actions, and as a valuable alternative to other engagement structures (Velasquez and LaRose, 2014).

Following this literature, we begin this study by asserting social movements, online political communities, and transnational policy networks constitute new options for political activism. We also assume that the Internet is an inherently democratic technology, enabling new forms of engagement with previously marginalized communities. In this view, the public sphere is expanded and takes on multiple forms, opening up new places from which to speak (Barker, 2012).

Activism today involves actions in favor of social processes, or actions advocating political change. It may include street protests, riots, direct action, singing protest songs, organizing strikes, attending town hall meetings or demonstrations, donating money, motivating colleagues to vote, volunteering for a campaign, or writing letters to political institutions. The news reports of youth-initiated waves of citizen-led activism, public disobedience, and protest, show numerous educated, unemployed, alienated young people reacting. Their common denominators provide an umbrella for diverse, global actions and movements. The Arab uprisings revealed youth sub-cultures interested in democratic participation and rejection of their elders' conventional politics (Kandiyoti, 2014). The US-based Occupy movement, the international and local campaigns of Change.org, and the Gezi Park protests in Turkey are also examples of ways youthdriven new media and actions impacted politics in the world, especially as are practiced in extreme situations. In these contexts, the new media really seemed to provide a redefinition of the public sphere.
Furthermore, because young people are early and enthusiastic adopters of new communication technologies, and tend to use new communication technologies more often than others do, we thought we would find that "ordinary" young people would be, like others (in the news) active in promoting changes, and thus be especially important to study. Young people reach vast audiences and can potentially quickly mobilize many participants through their social networks. They are also more likely than their older counterparts to interface with civic and political issues in this way. Our focus on youths also makes sense because the transition from late adolescence to early adulthood is a time of significant development of civic and political identities (Kahne et al., 2011).

This study examines, for our selected research participants (young adults in Turkey and the US), whether the new form of a public sphere is actually being created and maintained by their particular uses of social media. This cross-cultural study explores some global elements of social media activism. The countries are somewhat comparable, having distributed governments (including executive, judicial, and legislative branches (Aschner et al., 2009), and linked historical relations, which are multidimensional and based on the free-market economy. In Turkey during the anti-government Gezi Park protests in 2013, social media use increased sharply, and the Internet created a platform for horizontal communication, activist organization and political participation. Kreis (2017) argues political topics are common on social media. Comparatively, Bartels (2017) draws attention to the US political system's important democratic features-most notably, fairly robust civil liberties and elections that allow ordinary citizens to replace their rulers from time to time. However, he highlights that those features do not make it an ideal democracy, in a sense, due to substantial increases in economic inequality over the past 30 or 40 years, and refers to the term "unequal democracy." The most-popular subjects of conversation on Twitter in the US in 2015 were politically motivated; even on non-political blogs, users often engage in political discussions. As globalization increases the similarities in the political and economic fields around the world, major social and economic issues such as social inequality, poverty, discrimination and violence have the same features everywhere, in spite of their own local characteristics. On the other hand, there are fundamental differences between the countries in terms of political system, ideological spectrum, size and global roles. Thus, these differences also construct the motives for the research.

In this context, this study aims to examine if and how young people mobilize for activism; how they interpret local and global issues; and how young people use social media to response political issues. Also, we attempt to understand which factors stimulate the young to activism, and whether their motivation is powerful enough to resist the system. For this purpose, we have conducted in-depth interviews with students of Firat University and the University of Minnesota Morris. Especially, we have suggested young people may have a vital role in creating a new public activism on social media. This study makes a contribution to the literature by examining activism capacities of young people and their social media usage patterns.

\section{Literature review}

The literature on the role of the Internet and social media regarding democratization and digital activism has centered on a dichotomy between optimists and skeptics. Whereas the optimist view argues that the Internet and other forms of electronic communication contributes to a new kind of public sphere and potentially a new kind of democracy (Bohman, 2010), and assumes that the Internet might also promote social movements 
(McCaughey and Ayers, 2003), the skeptic view indicates some limitations of Internet-based activities. Accordingly, the Internet is unable to create the necessary trust and strong ties that are required to build a sustainable network of activists. These restrictions make clear that even an extensive digital action repertoire will not, and probably never will, be able to replace traditional forms of activism and face-to-face communication (VanLaer and VanAelst, 2010). Dahlgren (2014) also argues that social media do not automatically result in politics, protest and political participation, but have the potential to foster political struggles and engagement. Being in a political discussion online is an important step, but would not automatically constitute political participation.

When shaping individual and collective/group activity potentials, existing political structures may provide some information and critical interpretations of (limited) permitted forms of participation in formal, state-sanctioned political processes. Media content-making within political parties and organizations may provide some chances for youth participation, which later enable young people to develop civic competencies for their later citizenship (Pfaff, 2009, p 168). Online youth-led activist subcultures and political groups questioning or attempting to alter the status quo have recently claimed legitimacy as creators of vital oppositional spaces for politics and culture, by using new media for making spaces in which a wider diversity of individuals and groups are applying the technologies to help produce creative social relations and forms of democratic political possibility (Kahn and Kellner, 2012).

Some studies of the relationship between digital media and civic and political life focus solely overall levels of internet access (Gong et al., 2007), on politically oriented consumer/ user activities such as reading biased news about political issues (Garrett, 2009), or on the reading of Facebook as a primary information source (Bakshy et al., 2015). Twenty-first century media users and participants are surrounded by complex ecologies of divides, diversities, networks and communities. This changing landscape has created unprecedented opportunities for expressions and interaction, especially among activists and other political and cultural groups around the world. Social media and the other new media technologies might provide an opportunity for social groups to build their own interests and to create a counter-hegemonic deliberation environment against the dominant media culture, politics, and power (Lievrouw, 2012, p 472).

As, Cohen et al. (2012, p 4) assert, new media do have the potential to facilitate a more equitable distribution of political participation among young people from different racial and ethnic groups. If participatory political practices might parallel various social and interest-based online activities in which the youth are heavily engaged, then young people are better able than other age cohorts to share, create, and consume online. To such ends, this study thus specifically explores if learning through interactions with friends, family, and those with whom they share interests in the new-mediated realm translates into increased political engagement and/or activism. Supporting the optimism associated with the possible new diffuse, public sphere formation, Oyeleye (2014) champions the revolutionary potential of new media, contending that the recent noteworthy outbreaks of youth protests and uprisings across the world against long-running oppressive governments and against the hegemonic global commercial systems signal specific instances of breaking the silence on the part of youth, which as a social group has long been rendered mute and nondescript by the older society and generally ignored by those maintaining power.

Mascheroni (2015) argues that participation can be better understood as a socially embedded and contingent online/offline practice that is shaped by the interrelation between habitus, capital and fields, for young people's use of social media is diverse -young activists who engage in online and offline actualizing citizenship make political uses of social media, including citizen journalism and media activism; while by contrast young citizens who are more politically disenfranchised are actually engaged in a variety of creative uses of social media. Online platforms can be designed in an interactive way fostering two-way/multi-way patterns of communication. Increasing the use of online platforms to facilitate the participation of young people in policy processes also has consequences for policymakers in charge (EACEA 2010/03, 2013).

Seeing the broad use of the Internet for creating online civic engagement opportunities, cross-cultural studies about online activism forms have begun. Hara and Shachaf's (2008) crosscultural comparisons of online social movements identified characteristics of online peace movements in Japan and Israel, and noted the importance of cultural resonance influences and the ways cultural values/norms determine a universal concept like peace. Harlow and Harp (2012) examined activists in the United States and Latin America using social networking sites (SNS), and found that most respondents said their activism occurs both offline and online, although US respondents were more likely to say their activism took place mostly online because of their widespread social media usage, while respondents in Latin America are less likely to be online activists because of the digital divide. This exploratory study suggests that SNS can turn online activism into offline activism-a significant contribution to research linking changes in activism to the Internet and SNS. In order to contribute to the current and future studies, we also carried out a comparative cross-cultural study concerning social media activism patterns and aimed to figure out how our different political and social contexts affect online activism attitudes.

Relevant to our research, Güner (2016) draws attention to the possible effects of social media on politics in Turkey starting from May 2013, noting that while these new media shape the structure of policy through promoting "contentious collective action", social media do not produce a radical outcome such as a government change. Güner (2016) also highlights that although there is strong evidence that social media was influential in Gezi protests both as an organizational tool and as an alternative press, "the revolution is not just one tweet away, nor it will be tweeted." We know, every day, young people have the potential to create their own political media and commentary and share it on Facebook. We know they can talk back to politicians through a post on a blog or on Twitter. We know they can also circulate funny videos as political commentary and they can use sites like Foursquare.com to meet with online friends to participate in demonstrations or protests. The question remains, for this study, do most young people actually take advantage of the new technologies of 21 st century mediated communication to conduct activities we would traditionally see as political activism? What about the "ordinary times" and "regular citizens" not already identified as members of political groups or in established or adhoc movements? Are they making choices to behave politically, like those with more notoriety, because they are technically enabled and media literate?

In this study, by comparing the social media use, membership in traditional political groups, conceptualizations of political issues, decisions about information and opinion sharing, participating in any social movement, the differences and similarities between two youth cultures are examined. This analysis is important in terms of exploring if or when different political, cultural and social norms affect the political and social conceptualizations of young people. 


\section{Method}

In order to fully understand the global dimensions of social media activism, several descriptive and comparative studies researching young people's civic participation tendencies through social media will be necessary. Thus, this study merely enters the beginning of a conversation, seeking to identify similarities and differences among different youth cultures in our home countries; describing online activism practices in order to examine how "ordinary" young people use social media to participate in political and other discussions.

This research focused on what university students think about online activism and how they use the new media tools for activism in their lives. The focus group analysis was found to be appropriate method for studying the participants, due to the distinct advantage of collecting the data on the respondents' worldview. The focus group may be defined as an interview style designed for small groups, with a directed conversation among several people regarding a specific topic, issue or concern. The aim of a focus group is to stimulate discussion to determine how people think and act individually within a social group. The focus group process consists of designing interview questions, recruiting focus group members, holding the focus group, evaluating the focus group, and presenting findings (Brennen, 2013 , p 60,71). Using this approach, researchers strive to learn through a discussion about conscious, semi-conscious, and unconscious psychological and socio-cultural characteristics and processes among various groups. The informal group discussion atmosphere of the focus group interview structure is intended to encourage subjects to speak freely and completely about behaviors, attitudes, and opinions they possess (Berg, 2001, p 111). Morgan argues that focus groups are used to help people express themselves openly about sensitive issues, as well as to bridge social and cultural differences (as cited in Brennen, 2013, p 59).

We conducted interviews with people aged 18-24 years who are students of the Firat University (Turkey) and the University of Minnesota Morris (USA). During each in-depth interview, usually about $30 \mathrm{~min}$ in length, we used a semi-structured questionnaire that involved asking participants about their use of the Internet and social networking sites, the global and local scale of issues they follow, their participation in political parties and political communication in general. Additionally we noted any particularly compelling replies that provided insights to our key research concerns. We continued conducting and transcribing our findings, reaching a saturation point (in which no new analytical insights are gained) at similar stages in participant recruitment. We reviewed the summaries we created and quotes we selected as exemplary, to determine patterns in the ways in which participants offered their reports of levels of and reasons for political engagement and activism.

In this article, we summarize findings from data from 40 people from the Faculty of Communication of Firat University (Turkey), and 36 people from the Department of Communication, Media \& Rhetoric of the University of Minnesota Morris (USA). Regarding the participant socio-demographic details, in both of the populations we have similar numbers of female and male respondents, which may be related to our recruitment in Communication programs. We find that the majority of participants identify in the majority ethnicities for each region, although some US participants indicate identity labels as mixed, or "no answer". Students come from a variety of regions and from an assortment of economic groups.

We started collecting Turkish responses in 2015, and continued to collect US responses through 2016. That lengthy span of time allowed us to include and regard event-based increases of interest for some respondents, but also to create a better, overall, average-level general picture of processes of communication and political participation. This sample is small and specific but provides insights that are valuable beyond the case study itself. This analysis is important in terms of understanding the effects of different cultures on political and social conceptualizations of young people, and in terms of online activism patterns. In this study, we address the following questions:

What is the extent of traditional and alternative political engagement among the young in Turkey and the United States?

In what ways do they see social media uniquely functioning to spread diverse perspectives and political conversations?

What role does social media play to motivate people to action?

\section{Findings}

The interviews gave us a chance to hear, understand, compare and contrast participants' answers concerning their particular forms of online and offline activity and their political interests. To describe social media-use habits for our participants in the two nations, to see if there were great differences among the similaraged cohorts, and to detect if there was a geographic or a technology-access-related digital divide, we started our interviews by asking about social media use. We did not find differences to occur, but rather that both populations of college students had available tools and Internet access, but had slightly different daily use habits.

All Turkish students participating in the study use social media tools such as Facebook and/ or Twitter daily, or multiple times each day, on their mobile devices. Facebook daily use is common in the US as well, although several of those interviewed have started decreasing their use of the tool (they believe it is no longer "for people like them"). Some US participants use YouTube, SnapChat, Instagram, Feely, LinkedIn, blog posts and special, hobby-based discussions, but very few of the US participants interviewed use Twitter. (Although the American Press Institute's report on millennial's use of social media (2015) indicates Twitter is used by $1 / 5$ of the social media users of this age in the US, the sampled population did not follow the trend.)

Both populations-Turkish students and US students-received news, information about friends, and information about their society and social roles from new media. The respondents relied on those sources, and generally trusted them. They gained information from personalized, semi-private and/or filtered (or self-selected) sources regularly, but did not have similar daily information-seeking habits with traditional mainstream news sources, organized political entities, extended family structures, formal religious leaders, or other public institutions.

One Turkish female (age 23) noted, "It is good for the people who use the technology, but it is not available to everyone." This concern is relevant for our participants as they think about their role(s) in society, but for this study, as they were all university students, they all had access to and used new media regularly.

The issues of interest. The respondents' most politically-salient issues were explored in depth. Both Turkish and US students interpreted the assortment of general, "social" issues they see in their new media-feeds.

Turkey sample. Inequality of opportunity, violence against women, discrimination, class-based issues, democracy issues, poverty, unemployment, and conflicts in the Middle East are the most emphasized and discussed topics for the Turkish participants. For example, a female student (age 21) defining herself as deist, secular and Turk said that the capitalist system exploited the society and legitimized it. Another female student (age 22) who defined herself as Alevi and secular emphasized the same issue. She said: "Inequalities, unemployment and poverty are important problems for me. The ruling party (Justice and Development Party, AKP) is pushing the country to deep inequalities. While the masses are under the constraint of poverty, the ruling party is not doing anything." A male student (age 22) who said he was socialist, Kurdish and atheist highlighted the class and culturally based issues such as the ecological devastation, economic and social inequalities, work-related problems, and the violation of labor rights.

These interviews showed that Turkish respondents coming from dissident and minority groups had more critical thoughts and opposing arguments against the ruling party (AKP) and the capitalist world order than others.

US sample. American respondents mentioned interests in similar issues to their Turkish peers. Inequality of opportunity, race and policing practices, class-based concerns and environmental protections are seen as the most-important discussion topics. For US respondents, gender-identity issues were of-interest to an individual especially concerned with transgender rights, but even though some of the US participants were veterans, none mentioned an interest in conflicts in the Middle East. For instance, a female (age 19) said, "I want to be a social activist on social 
inequality, social class". A male respondent (age 22) said he was interested in the ISIS crisis because there were some reports of a Minnesota linkage to it. Without clear coherence of ideology, a male respondent (age 19) said, "I'm really interested in gentrification. So Native rights, Black rights, feminists rights that sort of thing". Moreover, the majority of American students followed the presidential election process in the US in November 2016.

Traditional political engagement: Identified membership in political, partisan, NGO organizations or youth social groups. One of the major themes exposed by the interviews was the extent of participation in organized activities in Turkey and in the USA. Since an organized society may feed opposing viewpoints about the ruling class, we questioned whether the young are becoming members of social change or activist groups. This concern aims to identify the specific potential of young people for creating or reproducing an organized society.

Turkey sample. Thirty-three percent of Turkish respondents (more males than females) identified as members of a political party or NGO. Sixty-percent of these female respondents stated they were members of HDP (The Peoples' Democratic Party), a pro-Kurdish and pro-minority political party in Turkey. The other $40 \%$ were members of Ulku Ocakları (The Gray Wolves), a Turkish nationalist or ultra-nationalist organization. Similarly, $55 \%$ of male respondents stated they were members of HDP. The other male students were members of TEMA, an environmentalist NGO aiming at reforestation and protection of the natural habitat, and AKUT (Search and Rescue Association). One male student was a member of TKP (Turkish Communist Party). Some identified themselves as a member of CHP (The Republican People's Party), ADD (Ataturkist Ideology Association) and TGB (Youth Union of Turkey). Some respondents who said they were members of organizations are members of an NGO such as Community Volunteers Foundation (TOG) encouraging young people to participate in social responsibility projects as volunteers.

Their new values, such as the rise of individualism and dissolution of organized social structure, have replaced the politicized, organized social groups. The respondents who are the part of political and social groups have attitudes against the dominant political structure in Turkey. Being a dissident, for these respondents, thus acts as a driving force that enhances one's opposition-block-status in these patterns of low-level organized society.

US sample. Many of the US students did not understand the intent of the question, and its suggestive linkage to political activism. Instead they discussed membership in groups like "Women of Color", the "Clear Sky Native Council", high school class activities run in and by their schools, or membership in church clubs. Although these groups may have taken a "political position" to enhance justice or to raise funds for a cause, these groups do not focus on political activities. Fewer than $10 \%$ of US respondents claim political party affiliations, although some stated preferences for local/national candidates, usually "liking" candidates as individuals rather than as party representatives. US respondents weakly align with the Democrat-Farmer-Labor party, the Republican party, the Green party, the Independence party or the Grassroots/"Legalize Cannabis" party. Although some participate in party-based actions, the majority of US respondents merely vote. Situated in Minnesota, where over $70 \%$ of registered voters attend the polls (high by US-standards), participants interviewed in the "off-season" were not especially interested in political party activity, or in using new media to spread party (or counter-party, status-quo questioning) ideas.
With nearly equal gender-distribution, US participants emphasized that their "activism" is related to organized, community volunteerism, church-based fundraising and charity activities, and/or local short-term government-sponsored or supporting initiatives. They also frame a good portion of their civic activity with communitarian sensibilities-focusing on ways their actions create benefits for themselves and for people like them/from their hometowns/faith communities/etc. - with the goals of supporting people they know in "real life."

Participation in civil society is a key element of democracy-as a sign of citizenship consciousness. Civil society maintains the public sphere, within which opinions are formed, developed, and exchanged, and creates important social spaces in which conversation, debate, and criticism take place, and government policies and ministers may be questioned. Our combined findings indicate our participants' low levels of activity within recognizable organized systems. These tendencies regarding participation in social and/or political organizations provide us insights to understand their democratic potentials.

Alternative political engagement: direct involvement in social movements or demonstrations. This information was gathered to see if, for interviewed participants, there is a connection between information access/issue knowledge and physical engagement in change-making or protest activities.

Turkey sample. When the Turkish participants were asked about joining social movements, we found differences between the female and male students. Particularly, the women's participation was at a low level, probably due to more-traditional gender roles, the conservative-religious influences of family, and their social environment. Females who did participate in social movements were against the ruling party and had left-wing political thoughts. Some activist students participated in Gezi protests, public meetings and marches denouncing 10th October 2015 Ankara terrorist attacks, pro-Kurdish political party meetings, and HDP meetings.

In general, being a supporter of the dominant ideology leads to inaction and resignation. On the other hand, being a supporter of the opposition gives rise to the specified actions. Overall, the protest movements in which Turkish university students participated have different features, in terms of the motivations and political aims. Also, although participants' activism patterns have small, specific effects, effects are not transformed into a robust, multifaceted social movement able to trigger whole societal changes.

US sample. US students in general did not spend as much time engaged with social movements as was anticipated. A very small number said they once-marched with an "Occupy-supporting" group, or held a sign for \#BlackLivesMatter, but most said they were not engaged with social or political movements. A male (age 19) from a low-income family, who works two full-time jobs, said he joined multiple May Day protests.

Although the US students are aware of anecdotal stories of YouTube citizen journalists and twitter activists, and say technology makes such activities possible, they recognize that they and many of their friends and contacts are not actually utilizing the tools in that way. Furthermore, they were aware they could use their phones and tablets to send messages for political organizing and meet-ups, but confessed they instead used those same tools for more-mundane forms of personal and in-group social connections among people they already see in "real-life" regularly. 
While the participation proportion of Turkish students in offline social movements and protest demonstrations is $1 / 2$, only $1 / 4$ of US students have participated in this kind of activism events. Political and social polarizations and unrests in Turkey have constituted a ground for the activism motivation, but nothing similar was happening in the US during the period of data collection.

\begin{abstract}
Alternative political engagement: Indirect involvement or reacting to political, social, economic issue through social media. This information was gathered to see if the users of daily social media integrate political ideas and arguments into the messages they create and share.
\end{abstract}

Turkey sample. Most Turkish students shared their own comments/views on political issues through social media. The majority of participants followed or joined a social movement or a campaign through Twitter, Facebook or activist websites. Unlike public demonstration activities, there was little difference between males and females regarding being this kind of "activist" via social media. This majority's social media usage means that social media create for them an active area for discussion and debate. Furthermore, we observed that their critical comments shared in social media coincide with Turkey's hot political agenda. Most of the respondents stated reactions about Ozgecan, who was murdered February 2015 as she resisted a rape attempt. The death caused public indignation and sparked protests across the country in the following days. Other hot topics and problematic issues for their social media activism include: PKK terrorism; the Soma Mine disaster; government's position against dissident journalists; and the government's response to opposition social groups.

A male student (age 24) emphasized labor issues such as minimum wage, unemployment, work-related accidents, and workers' deaths. The female respondents using the social media for activism stated they struggled for women's rights and against violence to women. One of the male respondents (age 23) said: "Yes, I reacted to many incidents. However, the emergence of realities is blocked consistently." Similarly, another male respondent (age 24) said he "did not expect to get a solution to social conflicts through social media." These statements by Turkish students implied the discussions and debates on social media were weak regarding really changing the general policies or creating any effect over politicians or over social groups, so they did not expect significant outcomes. In this respect, for Turkish new media users, it is necessary to question whether the "real power" of mainstream politics diminishes dimensions of social media impacts.

US sample. US student participants generally read many posts offered by a few "political" people they trust as agenda-setters or by friends they see as "opinion-leaders," but do not often initiate conversations and dialogues of an especially political nature. Online sharing is very common overall, but not especially focused on political speech/activities. Some recall joining others to take part in symbolic actions (such as changing one's Facebook profile for a day to support gay marriage rights after the Supreme Court approval, or to support Paris after bombings), but they decide to take that kind of action generally after they see others they like and trust are also taking the same stand. Some respondents said they signed petitions trying to remove laws or to change laws. For US students this kind of communication is considered "important" political speech, and a form of political engagement, but is not seen to be a result of formal membership in an organized group.
A Hispanic female student (age 18) stated that she shared her opinion on Facebook about a black man who was killed by New York police in July 2014, while (illegally) selling single cigarettes on the street. She continued, "That was something that I was very, like, verbal about on social media.... They used unnecessary force...." A female respondent (age 21) said that she did not participate in any protest but shared her political views via social media, and she added, "Yeah, a lot of times. I definitely think that I'm more open about my political views on social media just because of the fact that you're so disconnected from everyone else".

Several disliked political speech in a venue seen as primarily functioning as social, and will take steps to avoid, ignore or ban others when communication becomes "too political." For example, a female (age 23) told us she wrote "To all Facebook friends: I have to do homework, and to clarify: I DON'T want to start debates. I am NOT going to argue on my status, but if you believe in ..., you can delete me right now from your friend's list. It is a touchy subject as it is already and I have had enough people tell me I am in the wrong and I am stupid because I am ... and never will change. I have my views and so do others, but if you are going to hate me for not believing in..., then delete me. BYE. I seriously am done with you!” Additionally a male (age 22) told us he wrote, "Yup, it is only 2 months into the year and I am already tired of the politics. Honestly I don't care who or why you vote for someone. Just done. I just feel it is sad to be writing this. Instead of politics feeling like a chance for me to help the United States become a better country I'd rather not even listen/read/see anything about politics." In brief, the US respondents have simultaneously lost faith and decided to avoid conflict.

Social media's potentials: the powers and possibilities of online activism to create a new form of public sphere. This responsetheme gave us the opportunity to revisit the intersection between our participants' actual practices and their continued perceptions of technology-created possibilities. This is where we found discussions of participant's perceptions of the powers and possibilities of online activism to create a new form of public sphere.

Turkey sample. The majority of both female and male participants acknowledged that new media could have functioned as a kind of public sphere, by highlighting that they see the social media as a democratic arena. They also said they believe social media can be a reliable platform for quickly and efficiently conveying certain kinds of messages. While some Turkish students were uninterested in politics and did not create their political messages, most of them said they followed some political party or politicians on Twitter (and consumed messages from those in power). Therefore, they stated social media are not only a free domain but also a source of motivation, sparking political debates. Only a small portion (approximately one-fourth) of the Turkish respondents argued that social media does not have the power to change the world or has limited power. They also noted social media affect people getting information, but do not alter their political or social behaviors. Some pointed out the polarization of the national political environment in Turkey and emphasized that, in such a condition, everyone defends his or her position instead of listening and considering multiple ideas.

Some respondents argued online activism platforms are not particularly capable of motivating the public, lacking a determinant role over the government. They also pointed out, even if a web-based discussion platform was constructed to motivate the public for protest demonstrations, it would not be able to cope with the pressure of government over the activists and dissidents. A male respondent (age 24) said, "When the government 
implemented a censorship on the news media or impose a broadcast ban on an issue, we can follow the incidents and share our opinions via social media, especially Twitter." In general, Turkish students had a consensus that the Internet and social media allow to them to share ideas and establish new collaborations and communities for changing the world.

US sample. Similarly, the US respondents seemed to agree on the potential influence of social media on public matters. For instance, a male (age 22) said, "It's a force to be reckoned with. I'd say we've seen a few good examples of it this summer with the Ferguson problem. As long as you were sharing something that had the word Ferguson in it whether it's on Twitter or Facebook you can instantly connect with other folks around the country or the globe that are interested in it. For good or ill, this thing is here to stay." An Asian female (age 20) said, "That can go both ways, if you look at the Arab spring, Egypt pretty much had its whole thing through Facebook, because all the youth are pretty much on Facebook so it can be a good way to get people's attention but then you also have ISIS which isn't democratic, but it's a good way to get people's attention." A male (age 19) emphasized the importance of social media as an alternative news source. He continued, "There are a lot of issues that don't get mainstream media coverage, and social media sites are a great place to get less covered information."

The US participants recognize there are technological possibilities for all kinds of people to be political message/content creators, but see themselves mostly as media users going to new media for information and entertainment at equal levels. The US students do not have a habit of paying attention to traditional sources of politicized media messages, and also do not see political discussion or organizing as the reason new media are so popular. Instead, much like the Turkish students, they see an increasingly combative political climate, and for US students the response is increasing to choose to ignore or to filter out messages of diverse opinions that further debate, and to instead seek media that comes to a consensus about ideas, or that avoids controversy.

For both sets of participants, the potential to create and fill a discussion with political ideas are recognized, but these young people prefer being mostly politically passive followers, or unengaged members of the public.

Motivation(s) for social action: following politicians or political parties via social media. It is claimed that young people are not interested in conventional politics and that apathy is on the rise. No longer are youths viewed as potential activists taking to streets as in 1968, or as voting people joining established parties as previous generations did. Instead, it is thought that today's youth, if interested in politics are under the influence of individualism or internalized postmodern values (Wallace, 2003). Middaugh et al. (2016) have noted, with the Internet and social media, young people are more able to engage with, and participate in the political process and people of all ages increasingly trust new media because they invite participation through comments.

Turkey sample. In the Turkish sample, 29 out of 40 respondents said they support politicians via social media. Also, respondents are willing to participate in online discussions. When asked whether they sent their opinions to political actors about an incident, public policy, or law, the majority of female respondents however, said they abstained from sharing their idea or critical thoughts with the politicians. A female respondent (age 21) noted, "I do not share my opinion with them because I do not think that they will consider our thoughts." This expression summarizes Turkish opinions about the insufficiency of conventional politics to change based on this kind of participation.

US sample. In the US sample, 21 out of 36 respondents did not follow any political party via social media, although some followed Barack Obama, Hilary Clinton, or Bernie Sanders. Some had critical perspectives, a male student (age 19) said "I don't [follow on twitter]. I'm quite honestly very sick of politicians." When asked if they sent messages to politicians, they stated they did not send any message directly, but instead preferred using the re-tweet or "like".

This question was important for identifying the activist and dissident spirits of respondents. To react on a matter is a step beyond being a follower. Thus, it is an indicator illustrating young people's activism power. The different participative attitudes of the two samples point out differences in political culture. The Turkish political climate, with dissatisfactions highlighted after Gezi protests, was undergoing transformations at the time this study was conducted (Türkmen, 2015). While established and more stable, the US system creates a democratic life-world for its citizens, yet it also brings about many social and economic inequalities stemming from the practices of capitalism. The differences arising from the differing political cultures and historical conditions thus may shape our observed patterns of participation and democracy.

Trust in traditional political practices and structures. Trust in traditional politics is an important indicator of interest in maintaining existing political systems. Wallace (2003) argues young people are not strongly represented in traditional political parties and political debates-since conventional parties and discussions seldom consider young people's interests, young people themselves largely distance themselves from parties. Soleri-Martí (2015) finds declining voter turnout and formal political participation among the youngest generations, and an emergence of other forms of participation such as protests and political consumption. This diversification of the repertoires of participation leads to the rise and normalization of protest and political consumerism, and the emergence of post-materialist values in particular among the young. Thus, an alternative form of interest and involvement in politics has emerged. European Commission (2015) examined young people's general levels of interest in politics and ways young citizens take advantage of different opportunities to participate in politics actively, finding that traditional forms of political participation do not appeal to young citizens. Instead, they favor flexible and issue-based forms of active participation, such as contributing to projects of NGOs, participating in community-driven initiatives, joining social movements and expressing political opinions in public spaces and in social media to interact with public authorities and exchange views on political issues.

Turkey sample. The majority of Turkish respondents said they do not trust politicians, traditional politics and its mechanisms. This confidence crisis, which stems from the insufficiency of the representative democracy, has affected the participants' attitudes; and hopelessness has begun to increase among the young people in Turkey. Most of the respondents argued that politicians act in the line of their own interests. For instance, a female (age 24) said, "They (politicians) keep their interests before the public." Similarly, the other respondents emphasized that politicians work for their own interests and ignore the public's demands. Another female (age 23) who defines herself as a secular-modern expressed that the state was oppressive and authoritarian against citizens, and all people were not 
represented in parliament. A female (age 24) also mentioned that voting power is not enough for democracy, and that freedom of speech is restricted in Turkey. The male respondents had similar thoughts. A male (age 24) said that those who kept the state power in their hands had oppressed the public. Another male (age 22) indicated that politicians deceive the public by saying political lies. We find young Turkish people have quite negative thoughts related to politicians. Therefore, alternative participatory/political options offered by the Internet are attractive for young people.

US sample. For US participants, although they were possibly hesitant in trusting the traditional state apparatus, they saw few or no real dangers to contesting political leaders. This situation can be associated with American political culture; for they were confident America has systematically established the necessary elements of democracy, in spite of any recognizable, remaining personal boundaries to participation and the subsequent destructive effects of capitalism.

US students had opinions about politicians. They noted that it is one thing to "like" a social media post or photo-meme humorously criticizing a presidential candidate, but while doing so one still nonetheless endorsed the structures of government, the processes associated with elections, and the assumptions that outcomes would be calculated fairly and incorporated peacefully. In other words, politics in the US context was related to questioning small levels of decisions, but the structures of American society were not frequently themselves questioned by the types of "political" speech employed in the social media the studied participants recalled.

Some had views against traditional politics: A male (age 19) stated: “... I think that is a fairly extreme view, but I feel that capitalism has kind of extensively...disrupted the global order for many developing countries through imperialism and the corruption that it brings into the political process. Many of our politicians... are responding to corporations that fund their campaign. Money is becoming a huge part of politics. I think that this should be curved because of its influence in our government and how we're represented. I don't think that the people are as well represented as they were even 50 years ago."

An Asian American male (age 22) has also emphasized, with everything changing so fast culturally and socially that everybody had to be able to understand when it is best to change things to fit the current situation, not just (to) be a traditionalist. Also, a female (age 20) said that although she did not believe the system and would not go to vote, Obama was a really good president and there were some corruptions everywhere. She added, "If we are to get Bernie Sanders, he fixes our campaign systems and how we finance them, maybe that would go a down a bit to a more manageable level." A male (age 18) noted he did not trust the government saying “...the system is based on hundreds of years of racism, sexism, homophobia. You can't just change that overnight because you got a couple of good people..." Furthermore, most young people in the US were doubtful about their own abilities to affect real changes through new media messaging.

Our findings from our two sample groups have involved similarities and contrasts with young people's attitudes toward politics, lack of confidence in politicians, and their increasing disengagement from the formal political process (see in Henn and Foard, 2011). For both Turkish and US youth, institutional channels are distrusted, or cautiously approached. Those who are most skeptical about government are those who were uninterested or generally uninformed about politics. In general, it can be argued that young people today have little trust in the political parties, processes and professional politicians. This rationale may have a potential to trigger online political activism, although our participants are hesitant to believe that online activism (alone) with make significant structural changes.

\section{Conclusion}

In recent years, a common characteristic of popular uprisings and protests is the use of digital media to communicate, organize, and coordinate protest activities. Young people's role in promoting digital-based activism in established democracies requires serious scrutiny (Theocharis et al., 2015), and the associated use of social media by those not acting as activists, but as sympathisizers and readers of media created by advocates, needs attention also. Hence, this study analyzed when, how and why "ordinary" young people use or do not use social media to contribute to public activism.

At the beginning of this research, we explored some global dimensions of digital activism and focused on noteworthy reports of young people's civic participation tendencies through digital media and in terms of online activism patterns. Then, we particularly scrutinized different cultures with various political and social conceptualizations, to understand two cases-Turkey and the US-in greater detail. We did not find the strong activism spirit we expected. We made comparisons and found several differences and similarities (for different reasons).

This study is specific and descriptive, relating and evaluating the experiences, statements and perceptions of the college-aged participants we interviewed, living in particular cultures, during a particular time. Their experiences, education level, and national, ethnic, religious and social specifics shape the kinds of responses we have in this report. In other words, the characteristics of the samples determine the results. This means our findings are not generalizable, but are instead rich in details that provide insights. Our findings show that for the young people we studied, social media usage for activism and resistance (or participation) in politics is related to the ways they understand their possibilities for different positioning options in the local and global political culture. Although both nations are identified as democratic systems, there are persistent differences in the ways the concept of democracy is realized by the governments of Turkey and the US, and hence, the two populations, fully aware of limitations and possibilities, relate to their political communication options and risks differently.

For our respondents, the social media they choose to use are seen to possibly act as a public sphere or forum for political discussion. They use the media to become aware of topics and to be informed of issues of interest, but they tend to follow and read rather than initiate and lead. Because the tools they know well and use regularly allow anyone to be a media producer, they know they have a technical capacity to create democratic dialogue and plan political actions, but they rarely do so. Although we have reviewed literature about issue-based activism on social media, specifically, for our participants, we find that most are not deciding to use the media for mobilizations. Whether this decision comes from the perception that there is little need to activate, or that activation matters little (such as in the US, where there remains more faith in traditional modes of political and social action) can be inferred. Our findings suggest a relationship (especially weak in the US) between the levels of dissatisfaction with current political opportunities and the participants' willingness to state controversial or system-questioning positions. Furthermore, we are not seeing large-scale, organized social movements coming from the new-mediated discourse, but instead see youth responding to event-based, shorter-term political experiences. 
Our respondents noted that through social media they learn about issues and events more rapidly, that they get information and news primarily through social media, and that they make decisions about support based on how others respond. While that participatory politics possibility exists, for the students we interviewed in Turkey and the US, most of them were not using social media to participate in or protest any political processes. Instead, in the less-common instances when they used new media for political communication, they used it to reinforce already-held beliefs, to discuss with like-minded people, to create and share humor and to be informed of events as they happened. We found our university students were less willing to post or share controversial ideas, for fear of losing scholarships, risking public status, or alienating "friends". Although technology made it possible, they choose not to use new media in political ways, for they reasoned they communicate with a wide, but not very deep, collection of people to whom they are loosely-affiliated.

The possibilities for instigating online political discussions are recognized by our research participants in both countries, however among the university students in our study, they are not generally interested in using social media as a public sphere, and are unlikely to state strong positions or start discussions of topics unless they identify themselves as "dissident". In sharp contrast to the suggestions of the literature review and our initial assumptions, our findings reveal that for our research participants, social media merely revives their motivation to participate in mundane, lower-risk forms of civic and political life. They see that they could participate in discourse that could be issue-based, global and networked; and that they could be attempting to create a more-fair social experience or an improved worldwide democracy. From this study we cannot say new media nurtured public activism among young people, however, we still claim media may trigger youth activism or social movements. As seen in previous studies, the "traditional politics approach" based on representative democracy has not presented an alternative to young people, and new participative solutions for young citizens are attractive.

So, although there is a belief that social media could change the world, and new media technologies are seen to have revolutionary potentials, our respondents use media for more social and interpersonal needs. It has not changed their lives in the ways that political theorists have imagined, but new media technologies have nonetheless affected the lives of many people. The effect of social media might be limited but it should not be ignored, due to its creative and insurgent capacity. Social media has a key role in diffusing the messages into the public and in creating networks of resistance to counter dominant power structures. Furthermore, the similarities we found despite the very different contexts suggest that while mainstream media environments produce patterns that do not transform local political systems, social media create similar usage forms all around the world. We believe that qualitative cross-cultural studies related to social media activism will open new horizons to researchers, and our findings will inspire future studies. As Barrios-O'Neill (2015) noted, social media are either under- or overestimated in terms of benefits. This study provides data that weakens our initial over-estimation for social media activism, by illustrating the reasons for limited political messaging by young-adult social media users.

Received: 1 May 2017 Revised: 1 January 2018 Accepted: 2 January 2018

Published online: 10 April 2018

\section{References}

Aschner D, Bane R, Kaiser K, Sène JJ (2009) History and Culture of Turkey: From Anatolian Civilization to Modern Republic. Chatham University, https:// www.chatham.edu/academics/globalfocus/archives/turkey_1011/_pdf/ history_culture.pdf

Bakshy E, Messing S, Adamic LA (2015) Exposure to ideologically diverse news and opinion on Facebook. Science 348(6239):1130-1132

Barker C (2012) Cultural studies: theory and practice. Sage, London

Barrios-O’Neill D (2015) Social media: a critical introduction, Information. Commun Soc 18(12):1437-1439. https://doi.org/10.1080/1369118X.2015. 1050052

Bartels L (2017) To Make Our Democracy Functional, We Must Confront Economic Inequality. http://www.truth-out.org/news/item/41962-to-make-ourdemocracy-functional-we-must-confront-economic-inequality

Bennett WL (2003) New media power: The internet and global activism. In: Nick C, Curran J (eds) Contesting Media Power. Rowman and Littlefield, Lanham

Berg BL (2001) Qualitative research methods for the social sciences, 4th edn. Allyn and Bacon, Needham Heights

Bohman J (2010) Expanding dialogue: The internet, the public sphere, and prospects for transnational democracy (2004. In: Gripsrud J, Moe H, Molander A, Murdock G (eds) The idea of the public sphere: a reader. Lexington Books, Lanham, pp 247-269

Brennen BS (2013) Qualitative research methods for media studies. Routledge, New York

Cohen CJ, Kahne J, Bowyer B, Middaugh E, Rogowski J (2012) Participatory Politics: New Media and Youth Political Action. Youth and Participatory Politics Research Network, Oakland, CA

Dahlgren P (2014) Social media and political participation: discourse and deflection. In: Fuchs C, Sandoval M (eds) Critique, social media and the information society. Routledge, New York, pp 191-202

EACEA (2010) Youth participation in democratic Life (2013) LSE Enterprise http://www.lse.ac.uk/businessAndConsultancy/LSEEnterprise/pdf/YouthParticipationDemocraticLife.pdf. Accessed 17 Sep 2015

European Commission (2015). Commission Staff Working Document: Situation of young people in the EU, http://eur-lex.europa.eu/resource.html?uri=cellar: d4b27e70-5b8a-11e5-afbf-01aa75ed71a1.0001.05/DOC_5\&format=PDF

Garret RK (2009) Echo chambers online?: politically motivated selective exposure among Internet news users. J Comput Commun 14(2):265-285. https://doi. org/10.1111/j.1083-6101.2009.01440.x

Gong W, Li ZG, Stump RL (2007) Global internet use and access: cultural considerations. Asia Pac J Mark Logist 19(1):57-74

Güner SE (2016) The impact of social media on political change: Gezi protests in Turkey, Vol. 5, Issue 6 Centre for Policy and Research on Turkey (Research Turkey), Research Turkey, London, pp 88-99. http://researchturkey.org/? $\mathrm{p}=12181$

Hara N, Shachaf P (2008) Online peace movement organizations: a comparative analysis. In: Chen I, Kidd T (eds) Social information technology: Connection society and cultural issues. Idea Group, Hershey, pp 52-67

Harlow S, Harp D (2012) Collective action on the web, information. Commun Soc 15(2):196-216. https://doi.org/10.1080/1369118X.2011.591411

Henn M, Foard N (2011) Young people, political participation and trust in Britain. http://www.exeter.ac.uk/media/universityofexeter/research/microsites/epop/ papers/Henn_and_Foard_-_Young_People, _Political_Participation_and_Trust_in_Britain.pdf

Kahn R, Kellner DM (2012) Oppositional Politics and the Internet: A Critical/ Reconstructive Approach. In: Durham MG, Kellner DM (eds) Media and Cultural Studies: Keyworks. Wiley-Blackwell, West Sussex, pp 597-613

Kahne J, Middaugh E, Lee NJ, Feezell JT (2011) Youth online activity and exposure to diverse perspectives. New Media \& Society 14(3):492-512. https://doi.org/ $10.1177 / 1461444811420271$

Kandiyoti D (2014) Contesting patriarchy-as-governance: lessons from youth-led activism". http://www.opendemocracy.net, Accessed 7 Mar 2014

Kreis R (2017) \#refugeesnotwelcome: Anti-refugee discourse on Twitter. Discourse Commun 11(5):498-514. https://doi.org/10.1177/1750481317714121

Lievrouw LA (2012) Alternative and activist new media: a genre framework. In: Durhama MG, Kellner DM (eds) Media and Cultural Studies: Keyworks. Wiley-Blackwell, West Sussex, pp 471-491

Loader BD, Mercea D (2011) Networking democracy? Social media innovations in participatory politics. Inf Commun Soc 14(6):757-769. https://doi.org/ 10.1080/1369118X.2011.592648

Loader BD, Vromen A, Xenos MA (2014) The networked young citizen: social media, political participation and civic engagement. Inf, Commun \& Soc 17 (2):143-150. https://doi.org/10.1080/1369118X.2013.871571

Mascheroni G (2015) The practice of participation: Youth's vocabularies around on- and offline civic and political engagement. Media@LSE Working Paper series, 35. http://www.lse.ac.uk/media@lse/research/ mediaWorkingPapers/pdf/WP35-FINAL.pdf 
McCaughey M, Ayers MD (eds) (2003) Cyberactivism: online activism in theory and practice. Routledge, New York

Middaugh E, Bowyer B, Kahne J (2016). U Suk! Participatory Media and Youth Experiences WithPolitical Discourse. Youth \& Society. https://doi.org/ 10.1177/0044118X16655246

Norris P (2007) Political activism: new challenges, new opportunities. The Oxford Handbook of Comparative Politics. https://www.hks.harvard.edu/fs/pnorris/ Acrobat/Boix\&stokes-chap26.pdf. Accessed 12 Nov 2016

Oyeleye A (2014) Lost and found? Globalised neoliberalism and global youth resistance. Crit Arts 28(1):57-68. https://doi.org/10.1080/ 02560046.2014 .883689

Pfaff N (2009) Youth culture as a context of political learning: How young people politicize amongst each other. Young 17(2):167-189

Soler-i-Martí R (2015) Youth political involvement update: measuring the role of cause-oriented political interest in young people's activism. J Youth Stud 18 (3):396-416. https://doi.org/10.1080/13676261.2014.963538

Theocharis Y, Lowe W, van Deth JW, García-Albacete G (2015) Using Twitter to mobilize protest action: online mobilization patterns and action repertoires in the Occupy Wall Street, Indignados, and Aganaktismenoi movements, Information. Commun Soc 18(2):202-220. https://doi.org/10.1080/ 1369118X.2014.948035

Türkmen B (2015) From Gezi Park to Turkey's transformed political landscape. https://www.opendemocracy.net/buket-t\%C3\%BCrkmen/from-gezi-park-toturkey\%E2\%80\%99s-transformed-political-landscape

Wallace C (2003) Introduction: youth and politics. J Youth Stud 6(3):243-245. https://doi.org/10.1080/1367626032000138237

Wessel B (2014) Exploring social change: process and context. Palgrave, London

Van Laer J, Van Aelst P (2010) Internet and social movement action repertoires: opportunities and limitations, Information Commun Soc 13(8):1146-1171

Velasquez A, LaRose R (2014) Youth collective activism through social media: the role of collective efficacy. New Media Society, http://nms.sagepub.com/ content/early/2014/01/07/1461444813518391. Accessed 17 Feb 2015

\section{Data availability}

All data generated or analyzed during this study are included in this published article

\section{Acknowledgements}

The research for this paper was financially supported by TÜBİTAK (The Scientific and Technological Research Council of Turkey), which is the leading agency for management, funding, and conducting of research in Turkey (grant no: 1059B191501536). US student research assistants Erin Nichols and Braeden McDougall worked with support from the Native American Student Success Office and Programs and the NASANTI grant, U.S. Department of Education. Zachary Threadgill also worked as a US student assistant on this project. This research was approved by the University of Minnesota, IRB Code Number: $1405 S 50445$

\section{Additional information}

Competing interests: The authors declare no competing interests.

Reprints and permission information is available online at http://www.nature.com/ reprints

Publisher's note: Springer Nature remains neutral with regard to jurisdictional claims in published maps and institutional affiliations.

Open Access This article is licensed under a Creative Commons Attribution 4.0 International License, which permits use, sharing, adaptation, distribution and reproduction in any medium or format, as long as you give appropriate credit to the original author(s) and the source, provide a link to the Creative Commons license, and indicate if changes were made. The images or other third party material in this article are included in the article's Creative Commons license, unless indicated otherwise in a credit line to the material. If material is not included in the article's Creative Commons license and your intended use is not permitted by statutory regulation or exceeds the permitted use, you will need to obtain permission directly from the copyright holder. To view a copy of this license, visit http://creativecommons.org/ licenses/by/4.0\%

(C) The Author(s) 2018 